\title{
Comparison of Teacher Motivation for Mathematics and Special Educators in Middle Schools That Have and Have Not Achieved AYP
}

\author{
Margaret E. King-Sears and Pamela H. Baker \\ George Mason University, Fairfax, VA 22030, USA \\ Correspondence should be addressed to Margaret E. King-Sears; mkingsea@gmu.edu
}

Received 15 November 2013; Accepted 5 January 2014; Published 4 March 2014

Academic Editors: F. Jimenez, B. Marlow, W.-C. Shih, and G. Sideridis

Copyright (C) 2014 M. E. King-Sears and P. H. Baker. This is an open access article distributed under the Creative Commons Attribution License, which permits unrestricted use, distribution, and reproduction in any medium, provided the original work is properly cited.

\begin{abstract}
Mathematics and special educators who taught in middle schools that had or had not made Adequate Yearly Progress (AYP) were surveyed to compare their motivation across three domains on a Teacher Motivation Survey: Work Environment, Professional Identity, and Career Satisfaction. Educators from schools who had met AYP reported a significantly better Work Environment, also referred to as collective efficacy, than that of educators from schools that had not met AYP. There were no statistically significant differences for special or mathematics educators, whether from a school that had or had not met AYP. Other results from the Teacher Motivation Survey are presented, including qualitative analyses from open-ended queries in the survey. Implications for expanding this research as well as more immediate applications and actions for school administrators are noted.
\end{abstract}

\section{Introduction}

The No Child Left Behind Act of 2001 (NCLB) [1] in the United States of America set in motion a series of comprehensive actions based on, among other factors, students' performances on state assessments. Although NCLB requirements were initially instigated by the Bush administration and subsequent flexibility options available via the Obama administration, requirements for assessing students, disaggregating scores by specific subgroups of students, and annual testing with public reporting have remained in place. As a result, once a year, students across the United States (USA) participate in their state's assessments and, based on a given year's scores or in comparison to previous year's scores [2] as well as other state-specific individually-determined criteria, schools either achieve Adequate Yearly Progress (AYP) or not. Although there is variation among the states about assessment content (e.g., what skills in reading? What skills in mathematics?), the goal across states is to have students achieve at or above predetermined proficient levels (i.e., "pass" the test).
Whether a school achieves AYP or not has implications for instructional decisions for the upcoming year. When analyzing AYP data, administrators and educators determine curricular areas and student populations where continued work is needed in order to meet AYP criteria for the following year. Conversely, for schools who have met AYP criteria, school personnel focus more on continued achievement for students versus feeling more public pressure to increase the likelihood students will "make AYP" the next school year.

While NCLB has evolved under the leadership of the current administration (e.g., $[2,3]$ ), the continued emphasis on utilizing data to drive reform is clear. Secretary of Education Duncan [4] suggested early on that "To close the data gap-which now handcuffs districts from tracking growth in student learning and improving classroom instructionstates will need to monitor advances in student achievement and identify effective instructional practices" (para. 7). Given the role state assessment scores play, educators remain under considerable pressure to ensure that their students reach AYP proficiency levels. How these pressures affect educators' professional motivation and beliefs of their capacity to teach 
effectively varies. For example, Hemelt [5] found that schools that do not make AYP in both math and reading may not perform better in the subsequent school year. He posits this could be due to the school's capacity to respond or to "the demoralizing effects of broad failure" (p. 715).

Finnigan and Gross [6] pointed out that NCLB consequences for attaining AYP are built on the assumption that educators will increase their teaching effectiveness in response to students' assessment data. However, based on interview and survey data from educators in low-performing schools, Finnigan and Gross found conflicting reactions. Some educators at schools that did not achieve AYP targets were frustrated and less motivated, resulting in low morale that had a negative impact on the work environment. Other educators perceived a negative stigma when their school was on probationary status (i.e., had not yet attained AYP), yet they still felt determined to help ensure students achieved AYP targets. Particularly, educators who taught at schools that had not achieved AYP over multiple school years questioned their career choice, debating whether they should stay at a given school, or even continue teaching. Indeed, some educators at low-performing schools felt that they became the targets of whether AYP or progress toward AYP was achieved. That is, whether students they taught passed state assessments is reflected on them as educators. Whether students scored near the predetermined proficiency level was insufficient; students needed to score at or above proficiency levels or school-set goals for improvement.

Other researchers seeking to determine the impact of AYP on educators' motivation point to the critical role teacher self-efficacy plays. As a construct, teacher self-efficacy rests on educators' beliefs that they can bring about desired student outcomes $[7,8]$. Such beliefs are evident both at the individual (self-efficacy) and the group (collective efficacy) levels. Finnigan and Daly [9] found in their study on four schools that attaining AYP status remained difficult for many reasons, including that there was not a "collective sense of trust, support, and respect in these schools" (p. 64). Goddard et al. suggested that empowering individual educators to make meaningful instructional decisions influences their beliefs that the group can teach effectively. Conversely, educators who feel less control over instructional decisions, such as educators at non-AYP schools who feel decisions are thrust upon them, may have lower beliefs that their group actions can bring about effective changes. This can be particularly disconcerting for educators who instruct students with disabilities, one of the four subgroups for whom data are disaggregated on state assessments, in content targeted for state tests, such as mathematics [10,11]. Wong [12] indicates that NCLB's continued emphasis on disaggregated data for subgroups makes any achievement gap glaringly obvious. As such, educators are challenged to use responsive pedagogies when teaching any students, but particularly students from each of the four subgroups: students with disabilities, students who are economically disadvantaged, students who are English language learners, and students from different ethnicities.
Students with disabilities who are working toward passing the same state assessments as their typical peers are usually students with high-incidence disabilities (e.g., learning disabilities, high-functioning autism, and emotional disabilities). Although sometimes the students are taught content, such as mathematics, in special education self-contained settings, most often the students are in general education classrooms taught by mathematics teachers. In particular in middle and high school grades, mathematics teachers instruct students with high-incidence disabilities as part of a cotaught class (i.e., with a special education coteacher) or as the sole teacher in the classroom. As such, determining the perspectives of special educators and mathematics teachers because they are tasked with instructing students to do well on state assessments is a logical starting point for examining further how AYP status affects them.

1.1. Special Educators. Davies [13] commented that special educators can feel overwhelmed with the challenge of instructing students with disabilities to the AYP proficiency levels that seem more reasonable for their same-age peers. Byrd-Blake et al. [14] noted that although one intention of No Child Left Behind was to help close the achievement gap between and among students, the disparity continues in both reading and mathematics. Indeed, there is evidence that middle school students with disabilities who receive instruction in general education classrooms can benefit, as their peers can, when specific methods are used.

Billingsley [15], in her synthesis of research on special educators who stayed or left the field, found that work environment was the primary factor that influenced job satisfaction and career decisions. Work environment was defined as that consisting of school climate, which was influenced by support from colleague teachers and administrators as well as professional development opportunities. When work environment experiences were negative, special educators experienced higher stress and less career satisfaction, leading to attrition. Given the chronic shortage of fully certified and highly qualified special educators, improved work environment is necessary to increase the retention of beginning special educators. In many schools, it is the performance of students with disabilities on state tests that influences whether or not a school achieves AYP status [16]. Consequently, the motivation for special educators to persist in preparing students to do well on these tests is particularly relevant.

1.2. Mathematics Educators. From the most recent data on performance of 8 th grade students with disabilities in mathematics, an average of $67 \%$ scored below proficient (considered a "did not pass"), with a range across states and U.S. territories of $26 \%$ to $95 \%$ below proficient [3]. The majority of students with disabilities who take the same mathematics test as their typical peers are taught in general education classes by either coteachers (e.g., mathematics teacher and special educator) or mathematics teachers. These students with disabilities may have high-incidence disabilities, such as learning disabilities, emotional or behavioral disorders, 
or high-functioning autism. Per NCLB, their access to the general education curriculum in mathematics has challenged middle school mathematics and special educators to attain the balance of providing effective instruction yet at a pace that can be difficult for students with disabilities (as well as some of their peers) to achieve. Additionally, responsive pedagogies for students with disabilities may not yet be in the repertoire of their teachers (cf: $[11,17,18]$ ).

Since NCLB, there has been an increase in research noting how critical it is for teachers of mathematics to know the content, and know the content deeply (Tchoshanov, 2011) $[17,19-21]$. Although mathematics content knowledge is essential for all students, Hill [22] found it especially true for middle school students with disabilities, who tended to be taught by less experienced teachers who had lower scores on teacher content knowledge assessments. Hill comments on the subsequent impact on students' test scores for students taught by more effective teachers: "...more experienced and knowledgeable teachers migrate from high poverty schools and tend to teach in courses containing the most able students within their school" (p. 109). Winters et al. [23] found that mathematics teachers who started the school year teaching higher-performing students were more likely to stay in the classroom. As such, it is possible that educators who have the highest self-efficacy, individual or collective, for teaching mathematics to students with disabilities and other diverse learning needs are not seeking to remain in positions or at schools where their skills may be most needed. When educators are faced with teaching students, with or without disabilities, who are low performers in mathematics, there is some evidence that their motivation to stay in teaching declines.

In sum, mathematics and special educators can, and many do, work collaboratively toward assuring students with and without disabilities achieve AYP targets each school year. In some school years, the students succeed, while in other school years, students need to score higher. How, then, do mathematics and special educators who have invested time, energy, and effort into teaching students content on states' assessments feel when AYP targets are not met? How is their motivation impacted? Do they still hold high beliefs in their skills as individual educators as well as having high beliefs in what their schools' educators can accomplish the next school year? And what is the impact on their career satisfaction?

1.3. Motivation. Bandura's [24, 25] social cognitive theory holds that people are agents of change because they can intentionally make things happen. He characterizes the agentic perspective as the ways in which people self-develop, adapt, and self-renew when faced with changing situations. Agency is divided into two types: collective and personal agency, or collective and self-efficacy. Certainly, educators in schools where achieving AYP is a major goal realize that whether or not the school achieves AYP will result in a changing situation. Building on Bandura's social cognitive theory, we sought to ascertain educators' self-ratings in three key domains under the broader construct of motivation, described in the next sections: self-efficacy as professional

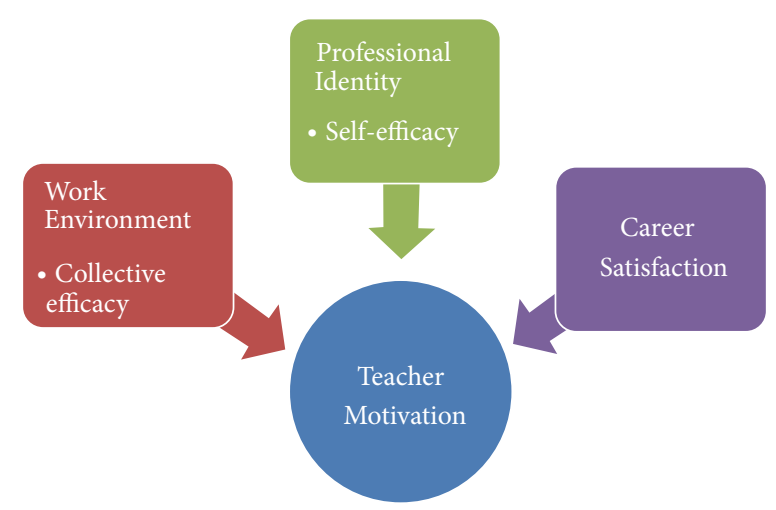

FIgURE 1: Factors impacting Teacher Motivation.

identity, collective efficacy as work environment, and career satisfaction (refer to Figure 1).

1.3.1. Self-Efficacy and Professional Identity. According to Bandura [26], personal efficacy, or self-belief, is critical; people have low motivation to persist in difficult situations unless they adhere to a foundational belief that they have the capacity to achieve the desired effects. When educators have high self-efficacy, they believe they will be effective in bringing about desired changes in students' learning. Conversely, if educators at non-AYP schools believe that their work environment is demoralizing and that their professional identity is negatively intertwined with their school's low assessment scores, they may have low self-efficacy. That is, they may believe they cannot effectively or sufficiently teach students to achieve high enough scores to achieve AYP status, which can impact their career satisfaction.

Further, Hoy and Spero [27] noted that educators with high self-efficacy are more open to adapt instruction to their students' needs. Such openness is particularly important when teaching students with disabilities and other unique learning needs (e.g., English Language Learners) because instructional decisions must be based on students' individual characteristics. Moreover, educators teaching at schools working to achieve AYP need a high degree of self-efficacy, so they can initiate, maintain, and sustain instructional persistence. Indeed, if educators do not believe that their actions and persistence can be sufficiently responsive to unique students' needs, then low self-efficacy results, which impacts morale and self-confidence.

1.3.2. Collective Efficacy and Work Environment. Collective efficacy is characterized by people's shared belief that they can work together to bring about desired results. Under such circumstances, the Work Environment is positive, supportive, and respectful. Colleagues are willing to and comfortable with sharing knowledge and skills with each other.

The Work Environment is not structured, perceived, or created in isolation from the individual's actions that influence how environments function. Collective agency is influenced by personal efficacy, which impacts personal motivation. Therefore, individuals who believe their actions 
can have the desired impact are motivated to act. For example, educators who believe their teaching can result in student learning are motivated to teach. Therefore, educators who have a strong Professional Identity feel they have control over instructional decisions, a voice on important school matters, and autonomy $[6,28,29]$.

1.3.3. Career Satisfaction. The interaction between collective and personal agencies (efficacy) influences teachers' satisfaction with their chosen profession over time. For educators, career satisfaction is represented by their desire to go to school each day, as well as the stimulation, enjoyment, and fulfillment they gain from their experiences as teachers. Thus, Ware and Kitsantis [30] found that self- and collective efficacy beliefs were predictors of degree of professional commitment. In their research, professional commitment encompassed the value and support teachers felt at the school level, their affective connection to teaching as a profession, and the ethical responsibility teachers felt that compelled them to continue in their career as educators. Given that professional commitment equates to job satisfaction, a goal of the current research was to determine the extent to which self- and collective efficacy were significant predictors of job satisfaction. Fisher [31] examined job satisfaction of novice and experienced secondary teachers. She found that for both groups of teachers, stress and burnout were indicators of job satisfaction, with stress as the more significant predictor.

As one might predict, as stress increases, job satisfaction decreases. In another study, E. M. Skaalvik and S. Skaalvik [32] noted that job satisfaction was positively related to teacher self-efficacy, with teacher burnout and emotional exhaustion negatively related to job satisfaction.

Stephanou et al. [33] found that elementary teachers' selfefficacy positively influenced their collective efficacy, which then influenced job satisfaction. Given that professional commitment equates to job satisfaction, a goal of the current research was to determine the extent to which self- and collective efficacy were significant predictors of job satisfaction. The current study also sought to determine if these same findings hold true today for educators challenged to achieve AYP.

In this research, the three domains of Work Environment, Professional Identity, and Career Satisfaction were identified as those that impact overall Teacher Motivation because they are reflected in the collective bodies of literature noted regarding collective and self-efficacy and the elements impacting retention and job satisfaction. The purpose of the study was to examine teacher motivation factors from educators teaching in schools that did or did not have AYP status in the previous school year (given that the current school year's status was dependent on the previous year's scores). Since the literature does not offer definitive perspectives regarding these questions, the study was based upon null hypothesis for each question as follows.

(1) There will be no statistically significant difference on the total Teacher Motivation Survey between teachers at AYP Yes schools and teachers at AYP No schools.
(2) There will be no statistically significant difference on each of the three domains between teachers at AYP Yes schools and teachers at AYP No schools.

(3) There will be no statistically significant difference in Teacher Motivation ratings between special educators and math teachers at AYP Yes schools and special educators and math teachers at AYP No schools.

(4) Work Environment and Professional Identity selfratings are not predictors of career assessment selfratings for educators who teach at schools that do or do not have AYP.

\section{Method}

2.1. Procedures. This survey was conducted in two MidAtlantic States in the USA in accordance with procedures approved by the university's institutional review board. The states selected offered a range of urban, rural, and suburban school districts. Each of the states selected measured AYP utilizing state-specific benchmark assessments. These two states were selected because the researchers had direct knowledge of the assessment systems, having taught and supervised student teachers in those states. Additionally, these procedures were aligned with those of other researchers examining teachers' reactions and actions related to AYP and NCLB in that researchers targeted participants from one or several states (e.g., [5]) or specific schools within a school district (e.g., Byrd-Blake et al. [14]). The protocol was a webbased survey with the electronic informed consent on the first page followed by five sections: Descriptive Information about School, Work Environment statements, Professional Identity statements, Career Satisfaction statements, and Descriptive Information about Respondents.

Potential participants were math and special education teachers in Maryland and Virginia in schools that contain a grade 8 . From this total population $(4,308), 25 \%$ of math teachers and special educators were randomly selected using Market Data Retrieval (MDR) services. MDR used a systematic method of acquiring emails for the random selection of educators targeted for receiving the Teacher Motivation Survey. This process yielded a total sample of 1,077 teachers to whom the online Teacher Motivation Survey (TMS) was sent twice. A paper version of the survey was offered upon request. First, an initial invitation to participate in research with the online link was sent. About ten days later, a second email was sent as a follow-up reminder, which also contained the online link for the survey. The survey data were collected at the end of school year, whereby schools where the participants taught had acquired their AYP status based on the previous year's high-stakes testing.

2.2. Participants. One hundred forty-four teachers submitted responses to the survey; 131 provided useable data, resulting in a response rate of $12 \%$. Although this is a low response rate, it exceeds the 2-3\% rate reported by Rigol and Ziemnicki [34] relative to school-based campaigns recruiting teachers or administrators for participation in research. The percent also exceeds that of similar online surveys (cf: [35]), albeit higher 
response rates are desirable. In addition, Halbesleben and Whitman [36] suggest that "response rates are an incomplete assessment of survey data quality" (p. 913). Strategies to increase response rate were utilized by offering a paper survey alternative to the electronic version and highlighting the value of responding to a topic of interest in the correspondence with the targeted group. Additionally, incentives were provided to attempt to increase the response rate (e.g., raffles for items such as iPod).

Approximately $60 \%$ of the participants represented schools who had achieved AYP the previous school year $(n=$ 78 ) and $40 \%$ represented schools who had not achieved AYP in previous school year $(n=53)$. Over $70 \%$ of participants ( $n=93$ ) expected that their schools would meet AYP in the current year. When dividing teachers into groups based upon their years of experience, $50 \%$ of AYP Yes participants were in the early stages of their career (10 years or less), $28 \%$ were mid-career (11-20 years), and 22\% were veteran teachers (more than 20 years). When these same parameters were applied to participants from AYP Noschools, teachers were reported as follows: $34 \%$ early career, $34 \%$ mid-career, and $32 \%$ veteran. Participating schools were mostly in suburban areas (65\%), with an additional 19\% in rural and $16 \%$ in urban locations. Forty percent of the teachers responding were general educators with at least some math responsibilities $(n=52)$ and $60 \%(n=79)$ were special educators. The teachers reported that $59 \%$ of their current administrators had been at the school for four years or less.

While nonresponse bias is always a concern, one strategy to address this concern is to compare the sample with the greater population [36]. Therefore, characteristics of participants in this research compared to characteristics of secondary educators from a national data set [37] are identified as one way to ascertain the extent to which participants in this study match characteristics of secondary educators nationally. Brackets indicate the percentage from a national data set. In the TMS study, $16.1 \%$ [17.6\%] of educators were under 30 years old, 22.9\% [25.6\%] were between 30 and 39 years old, 19.1\% [23.2\%] were between 40 and 50 years old, and $42 \%$ [33.7\%] were over 51 years old. There were $21.4 \%$ [41.7\%] males in this study, and 78.6\% [58.3\%] females in this study.

2.3. Measure. The Teacher Motivation Survey (TMS) was developed by the researchers based upon a review of instruments previously used on similar topics (e.g., [38-41]) as well as other relevant items, given the focus of this study. Initially, a series of statements were developed, and then the process of expert review for content validation occurred. Subsequently, six domains were reduced to three domains, preceded by a section acquiring school-based descriptors and concluding with queries about the characteristics of the participants. The final version of the instrument included the following sections: (a) Descriptive Information about Your School, (b) Work Environment, (c) Professional Identity, (d) Career Satisfaction, and (e) Descriptive Information about You.
While the majority of prompts were forced choice (e.g., Likert-based or check boxes), some open-ended opportunities were also offered (e.g., explain a forced-choice response, list perspectives, or make open comments). For the Likertbased statements in the domains of Work Environment, Professional Identity, and Career Satisfaction, ratings were as follows: 1 = strongly disagree, $2=$ disagree, $3=$ agree, and $4=$ strongly agree (refer to the Appendix in Supplementary Material available online at http://dx.doi.org/10.1155/2014/790179 for the domain-specific statements).

In the Appendix, all statements for each of the three domains (Work Environment, Professional Identity, and Career Satisfaction) are identified. At the end of each domain, an open-ended prompt invited participants to type any other information they would like to share with the researchers related to that domain. Additionally, at the end of the entire survey, a fourth open-ended query invited participants to share any other information with the researchers related to the topic of the survey.

Reliability scores for the instrument were calculated using Cronbach's alpha, resulting in .85 for the Work Environment subscale, .86 for the Professional Identity subscale, .91 for the Career Satisfaction subscale, and .93 for the total Teacher Motivation Survey. In addition, ancillary demographics (21 items) and qualitative (4 items) responses were obtained to ascertain emergent patterns and enhance the understanding of the quantitative comparisons.

2.4. Research Design. The study used a causal comparative mixed methods design in which the independent variable of AYP status during the previous school year was measured by participants' response to a single forced-choice item (Met AYP or Did Not Meet AYP in the previous school year) to address the first three research questions. Additionally, for Research Question 3, data were analyzed by separating special educators from math educators at AYP Yes and AYP No schools. The dependent variable of teacher motivation was determined via subscale and composite scores across 46 Likert-type items in the domains of Work Environment, Professional Identity, and Career Satisfaction. For Research Question 4, a causal comparative mixed methods design was used to determine if Professional Identity and Work Environment were predictive of Career Satisfaction for all participants.

2.5. Data Analysis Plan. The independent variable of AYP status was measured by participant response to a single forced-choice prompt used to create two distinct categories for comparison (i.e., Met AYP or Did not meet AYP in the previous school year). The dependent variable of Teacher Motivation was determined via subscale and composite scores across Likert-type items in the domains of Work Environment, Professional Identity, and Career Satisfaction. All quantitative data were analyzed using the Statistical Package for the Social Sciences software. A series of $t$-tests were conducted to address research Questions 1-3 and a regression analysis was completed to address research Question 4. 
In addition, participants were also given an opportunity to expand upon the forced-choice prompts in the TMS regarding each of the three subscales and to the overall survey. The responses to these four prompts were sorted by AYP Yes and AYP No and analyzed systematically by applying a constant-comparison method [42]. Independent reviewers coded the participants' open-ended comments to determine initial categories. Categories were then clustered to discern themes. The thematic categories were reviewed as a team (i.e., two doctoral students and the two researchers). When responses were categorized differently between the reviewers, discussion occurred until agreement was reached.

\section{Results}

The types of qualitative responses regarding all three subscales were similar regardless of whether or not the participants were from AYP Yes or AYP No settings. Both groups shared a variety of frustrations and successes centered upon the people with whom they work (e.g., administrators, colleagues, students, parents), the place itself (e.g., school, district, county), and even the overall state of education in this country. When rating each separately coded item for tone (e.g., positive, negative, neutral), positive comments from teachers in AYP Yes settings represented $29 \%$ of their comments; positive comments from those in AYP No settings represented $28 \%$ of their comments.

3.1. Total Motivation Scores. The averaged self-ratings for all three domains were calculated per AYP group to determine whether there was a statistically significant difference on the total TMS between teachers at AYP Yes schools and teachers at AYP No schools (Research Question 1; refer to Figure 2). Teachers in schools where AYP success was reported for the previous school year had higher mean scores on TMS overall (3.12 AYP Yes to 3.02 AYP No) (see Figure 2 for a graphic display of all domains and TMS overall mean scores). Significant differences were not present when a $t$-test was used to compare the two groups for the total TMS, $t(129)=1.516$, $P=0.13$ (two-tailed). Therefore, the null hypothesis was retained.

3.2. Subscale Perspectives. The averaged self-ratings for each of the three domains of Work Environment, Professional Identity, and Career Satisfaction were calculated per AYP group to determine if statistically significant differences on each subscale were present between teachers at AYP Yes schools and teachers at AYP No schools (Research Question 2). Teachers in schools where AYP success was reported for the previous school year had higher mean scores on each of the three subscales. Teachers from AYP Yes schools reported a significantly better Work Environment, also referred to as collective efficacy $(M=3.12, \mathrm{SD}=0.415)$ than did their AYP no counterparts $(M=2.97, \mathrm{SD}=0.416)$, $t(129)=1.954, P=0.05$ (two-tailed). A significant difference was not present with respect to AYP in Professional Identity $(P=0.24)$ or Career Satisfaction $(P=0.49)$.

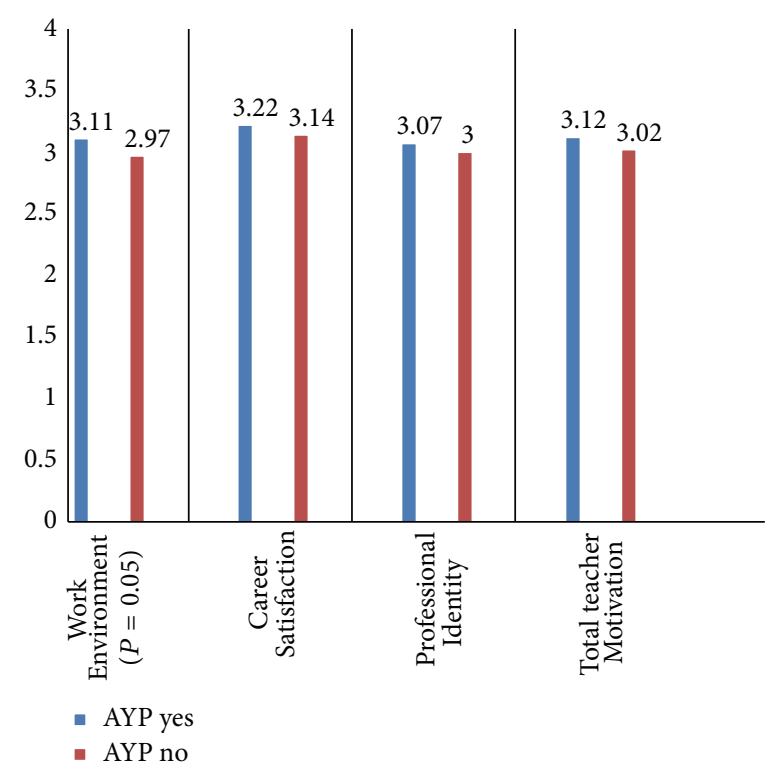

FIgURE 2: Visual comparison of means per domain and total TMS.

Therefore, the null is rejected since a significant difference was found to exist on one of the three subscales. Specific insights regarding each of the domains were obtained by analyzing participant responses to three qualitative prompts connected to the three domains (Questions 2.5, 3.2, and 4.5).

3.2.1. Work Environment. Relative to Work Environment frustrations, participants shared a variety of candid comments. "Students have become increasingly disrespectful directly to teachers" (AYP No). "In our county most parents are very outspoken and involved in their children's school activities - and feel free to question the teachers and call the principal! I feel strongly that teachers today have a target on their backs" (AYP Yes).

Concerns regarding other teachers were shared as well: "Some of the teachers I work with are inadequate or do not want to change their teaching methods. This creates issues in learning in the classroom" (AYP No). Issues with administrative support, especially relative to management of student behavior, were mentioned by both groups. "Discipline management at the administrative level is low" (AYP No). "Students with poor behavior are left in the classrooms. This steals from the instructional time of those students who are in school to learn" (AYP No). "Our administrators are cold, ineffective "textbook" people" (AYP Yes). "We thrive despite being micromanaged by incompetent leadership" (AYP Yes). Comments from both groups also addressed assessment, noting that "Testing is ruining public education" (AYP Yes).

But comments regarding Work Environment were not all negative. In fact, $48 \%$ of the AYP Yes comments were positive and $29 \%$ of the AYP No comments were positive. Teachers in both groups noted their satisfaction with opportunities to make a difference for their students. "I feel like a very important person in the lives of my students" 
(AYP No). Some participants from each group also had positive experiences with administrators. "I feel that we have a strong administrative team that is generally supportive of the teachers" (AYP Yes). Some participants indicated that professional development opportunities have been readily provided while others offered suggestions that the school needed more resources or that teachers needed more time to collaborate. Some participants provided personal rather than professional reasons for viewing the Work Environment as a positive (e.g., close to home, benefits). Occasionally, someone proclaimed, "It is a great place to work!" (AYP No).

3.2.2. Professional Identity. Relative to Professional Identity, a similar pattern of responses across the two groups was found. Interestingly, many comments were of a clarifying nature. Some were proclamations such as "Students need to be valued and respected for who they are and where they are in their learning" (AYP Yes) or "the public no longer places the value on education it once did" (AYP No). Other clarifying comments placed conditions upon success. "I am effective in the classrooms that have teachers that are progressive and use many methods in their teaching" (AYP Yes). Many comments were centered upon workload issues and instructional/curricular concerns, especially regarding accountability initiatives. "We are encouraged to base decisions on student progress but when expected to adhere to the almighty timeline of testing there is not the time necessary to move according to students' needs" (AYP Yes). Several participants noted that the content has been allowed to become boring due to the need to teach to high-stakes tests. "I feel like our state standards are a mile long and an inch deep with no real focus on teaching students to think mathematically or to enjoy the subject" (AYP No).

The issue of autonomy surfaced as well, with obvious paradoxes in experience reflected in these comments: "One of the reasons that many teachers remain at this school is that there is a great deal of autonomy in the strategies and methods that we employ in our teaching" (AYP No) versus "Teachers at my school are told what and how to teach ... there is NO "trust" of a teacher's ability to know their students and chart a course for success" (AYP No). The comments regarding issues impacting Professional Identity were heavily negative for the AYP Yes group at only $19 \%$ positive; of the comments shared by the AYP No group, 31\% were positive.

3.2.3. Career Satisfaction. Comments regarding Career Satisfaction reflected similarities once again between the two groups. In each case, some of the topics already discussed were re-emphasized, such as behavior, administration, assessment, and workload. However, additional topics surfaced that had not previously appeared in the comments. Some were relative to a more global perspective on teaching as a whole. For instance, "Lately I am not as excited about teaching as I once was" (AYP Yes) or "After 12 years of teaching, I have lost the joy of teaching due to the lack of flexibility in what and how I teach" (AYP No). Others spoke very specifically about the pay and support deficits in the profession noting that "Teachers NEED more support-financially and with the

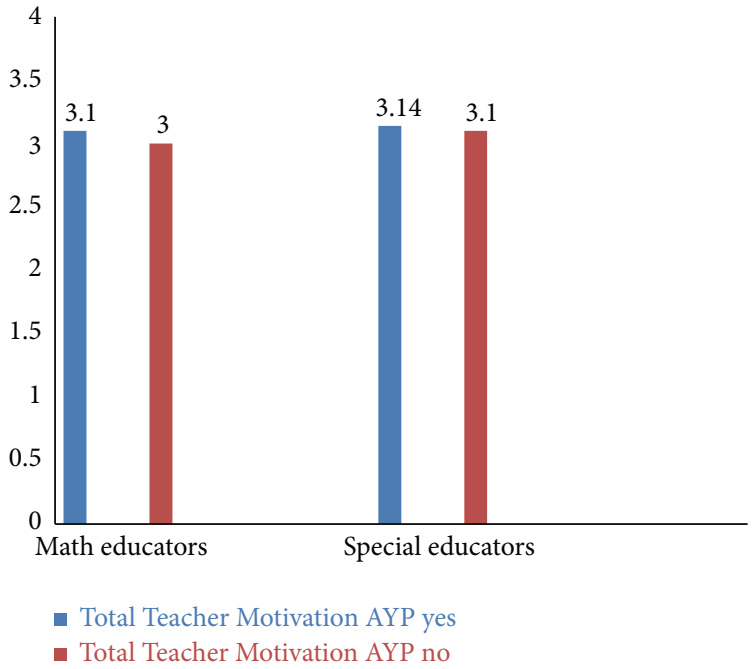

FIGURE 3: Visual comparison of means for math educators and special educators separated by AYP status.

public! Most teachers I work with are truly "unsung heroes" (AYP Yes). Both groups expressed $21 \%$ of their comments from a positive perspective, sharing observations such as "The relationships you build with students and parents is priceless" and "I left teaching for two years to work for a nonprofit and came back really valuing the difference I can make as well as basically being my own boss" (AYP No).

3.3. Special and Math Educators. Analyses of special educators' and mathematics educators' ratings, separated by AYP status, were conducted to determine if there were statistically significant differences between the two types of educators (Research Question 3). Mean scores on the overall TMS were slightly higher for participants from AYP Yes schools, but no significant differences were found $(P=0.69)$. Mean scores for AYP Yes educators were 3.1 for Mathematics and 3.14 for Special Educators. Mean scores for AYP No educators were 3 for Mathematics and 3.1 for Special Educators (refer to Figure 3). While scores for each group of educators were higher in AYP Yes settings for Work Environment, Professional Identity, and Career Satisfaction, no significant differences were present ( $P=0.422, P=0.949, P=0.854$, resp.). Scores for Special Educators (se) were higher in the Work Environment (Mse $=3.19$ versus $\mathrm{Mme}=3.00$ ) and Professional Identity (Mse $=3.08$ versus $\mathrm{Mme}=2.97$ ) domains; however, scores for Mathematics Educators (me) were higher in overall Career Satisfaction $(\mathrm{Mme}=3.20$, Mse $=3.18)$ regardless of AYP status. None of these differences were significant, so the null hypothesis was retained.

3.4. Predicting Career Satisfaction. Research Question 4 focused on whether educators' ratings in the domains of Professional Identity and Work Environment were predictive of their Career Satisfaction. For this research question, all educators' data were averaged per domain (i.e., no separation for AYP Yes or AYP No schools), and a regression analysis was conducted. Regression results indicated the overall model 
of two predictors (Professional Identity and Work Environment) significantly predicted Career Satisfaction, $R^{2}=$ $0.367, R^{2}$ adj $=0.834, F(2,128)=37.131, P<0.001$. This model accounted for $36.7 \%$ of the variance in Career Satisfaction. In addition, the relative importance of each predictor was assessed; results indicated that only the Professional Identity part of this variable set was a statistically significant contributor to Career Satisfaction $(P<0.001)$.

A summary of the relationship between each predictor and the dependent variable can be found in Table 1 . When further separated by AYP status, no additional significance was found $(P=0.886)$, affirming that only Professional Identity (personal self-efficacy) was significantly linked with overall Career Satisfaction for both groups. Subsequently, the null hypothesis was rejected.

At the very end of the survey, participants were offered the opportunity to share any additional comments regarding the content of the survey (Question 6.1). The respondents made their own connections among the domains relative to overall motivation. Many offered in-depth comments and broad-based observations both about their own situation and education as a whole. Some participants returned to topics already noted. For instance, NCLB [1] and highstakes assessment continued to be viewed as unfavorable by both groups. Struggles with discipline and administrative decisions were emphasized again.

However, new, and sometimes surprising, insights were also shared. "If a teacher does not believe that a student can overcome their obstacles in order to be successful, they are negatively impacting our youth" (AYP Yes). The respondents frequently linked environment and identity with career satisfaction. "So much of a person's work satisfaction in a school stems from the leadership and integrity of the administration" (AYP No). "I think the school atmosphere can make or break a teacher and it was interesting to think of the statements you presented" (AYP Yes). Teachers also conveyed how much they appreciated being heard, but with reservations regarding the tone they may have presented. "It is a shame the administration of my school district does not care to know what I just told you" (AYP No). "I feel like I have (quite sadly) answered this survey in a very negative manner. I feel bad about that, but I have been honest about: student apathy, administration noninvolvement (on a professional level), the feeling of being "trapped" in my content and in my job as a teacher in general" (AYP Yes). Finally, some participants wanted to make sure that it was clear how differently they feel about teaching compared to where or what they teach. "I do not wish to give the impression that I do not like teaching-I love teaching" (AYP No).

\section{Discussion}

4.1. Teacher Motivation as a Malleable Trait. Teachers at both AYP and non-AYP schools were motivated to teach. Although means were slightly higher for AYP Yes settings, they were not significantly higher. The results of this study indicated that the strength of one's Professional Identity (i.e., selfefficacy) can outweigh the impact of AYP relative to overall
TABLE 1: Summary of predictor variables in final model for Career Satisfaction.

\begin{tabular}{lcccc}
\hline & $B$ & $\beta$ & $T$ & $P$ \\
\hline Work Environment & .099 & .080 & .868 & .387 \\
Professional Identity & .752 & .551 & 5.965 & $.000^{*}$ \\
\hline
\end{tabular}

${ }^{*} P<.001$.

motivation. Work Environment (i.e., collective efficacy) was most subject to influence of AYP status, which indicates one area where school leaders could focus for educators at AYP No schools. To that end, Finnigan and Daly [9] found that teachers at newly sanctioned (e.g., AYP No) schools were more willing during that first year to connect or collaborate with colleagues than in later years. As such, that first year of AYP No status can provide not only a unique but also possibly the only opportunity to develop a collaborative climate leading to collective efficacy. Because administrators (i.e., school leaders) at AYP No schools are perceived as the instructional leaders, our discussion also focuses on the critical roles they play in shaping and influencing teachers' motivation.

Mean scores for educators at AYP No schools were not much lower than those at AYP Yes schools in our sample for Work Environment. This could indicate that educators feel much collective efficacy, as measured by Work Environment, whether their school has or has not already attained AYP status. School leaders need to be aware of the needs of frontline educators in making changes to gain or maintain AYP. Teacher Motivation may be a malleable trait; policy makers and administrators should seek input from teachers regarding motivation and put interventions in place when such queries indicate low motivation levels. Indeed, ByrdBlake et al. [14] found in their study of teachers' morale in four schools in urban high-poverty schools in Illinois, as influenced by NCLB requirements, that secondary teachers rated their administrators less effectively compared to elementary teachers. The researchers posited that one reason for the less effective ratings in secondary schools may be the culture and climate of how differently elementary and high schools operate, as well as the complexities of secondary schools in general. As such, techniques that work in elementary schools may not be the same ones as those that work in secondary schools. Administrators seeking to increase secondary teachers' motivation should examine the work environment more closely to determine what aspects are of concern, query teachers about desired changes, and include the teachers in the decision making about interventions that can increase their motivation. Most likely, those interventions will focus on actions that impact the teachers' areas of concern, which may then impact teachers' motivation. That is, increased teacher motivation may occur as a result of concerns being addressed, actions taken, and participation in decision making; it is important to acknowledge that teacher motivation is not targeted, but that actions that impact teacher motivation are the focus.

For administrators in AYP No settings, targeting motivation as a vehicle for change should be beneficial. E. M. Skaalvik and S. Skaalvik [32] found that collective efficacy was 
most strongly related to support teachers felt from leadership at their schools, indicating that administrators need to be both aware of and responsive to the kinds of support teachers at their school desire. Similarly, Stillman [43] notes teachers who taught needy students could stay motivated to use innovative techniques when administrators acknowledged the tension between the students' levels and the testing targets, yet promoted teachers' use of new techniques.

The role of Professional Identity, while being less related to AYP status than Work Environment, is seemingly important for overall Career Satisfaction. Viel-Ruma et al. [44], in a similar study that focused on responses from 70 special educators in one school district, also found a significant relationship between teacher self-efficacy and job satisfaction. While the model of Work Environment and Professional Identity together predicts slightly more than a third of Career Satisfaction, the strength of this connection is in the Professional Identity subscale, which represents self-efficacy. Therefore, this would imply that personal self-efficacy is more linked with overall Career Satisfaction than is the group's collective efficacy.

Again, these results concur with those from Viel-Ruma et al. [44], who did not find a significant relationship between collective efficacy and job satisfaction in their research. This would also indicate a certain level of resiliency relative to one's Professional Identity and Career Satisfaction regardless of the AYP status of the collective environment in which one works. AYP status was not significantly connected to either of these subscales. Additionally, a teacher's sense of Professional Identity (i.e., self-efficacy) may be more important for, although not dismissive of, Work Environment (i.e., collective efficacy) in terms of achieving greater Career Satisfaction.

Teachers' self-efficacy, however, is not only influenced by techniques they may need to learn, but also by techniques and content areas they already know, yet must defer that content and those techniques to instructional time focused on areas tested on states' assessments. For example, Wills and Sandholtz [45] describe "constrained professionalism" as situations in which teachers retain independence in making instructional decisions in their classes, yet those decisions may be influenced, or constrained, by the reality of the test-based contexts in which they teach. To that end, these researchers maintain that there are elements directly related to Professional Identity that are negatively impacted. That is, capable teachers may realize other content and deeper learning, in both tested and untested subjects, is set aside in deference to the focus on content on states' tests.

The differences across the types of teachers who participated in this study, math educators and special educators, were minimal. We find it interesting that the special educators lacked the same level of Career Satisfaction as did their math education counterparts in spite of having slightly higher motivation from the Work Environment and Professional Identity. The qualitative comments provide some insight into these findings. Many of the workload and paperwork burdens noted in the comments were related to special education.
4.2. Administrators Impact on Teacher Motivation. For all participants, over half of their administrators, regardless of AYP status, had been at the current school for four or fewer years, indicating the relative newness of the principal to a given school. Other researchers have expressed concerns regarding the high turnover rate for principals, although it is unclear from studies (including ours) why principals at some schools are within a relatively new phase of their tenure $[46,47]$. Additionally, Coelli and Green [48] provide evidence that "...when we allow for the possibility that it takes time for principals to have their full effect on a school, we find ... individual principals can have substantial impacts ... if given enough time at a school to make their mark." (p. 107) The researchers found that high school principals are at the same school an average of three years, which is insufficient time for them to fully realize their capacity to affect student outcomes. Consistent with the literature on bringing about reform and change in schools (cf: [49]), these data provide some evidence that switching administrators may be inadvertently undermining desired change at schools. Given the challenges of attaining or maintaining AYP Yes status for all schools, judicious decisions for providing support for administrators as school-based leaders may be prudent.

Educators acknowledge that their principals influence their motivation. In addition to implications for how schoolbased leaders can positively influence educators' self- and collective efficacy, it is instructive to note what influences schoolbased leaders' efficacy. Leithwood and Jantzi [50] found that school-based administrators' self- and collective efficacy are influenced by how well the school district creates conditions at the systemic level to provide organizational support, manage instructional programs, and promote collaborative work. Consequently, teacher motivation must be viewed not only as support needed from their administrators, but also as support that their administrators need from district leadership personnel. Given that approximately one third of U.S. schools did not make AYP in 2008-2009 (Center on Education Policy, 2010) [51], considerable pressures remain at all levels, but particularly for those who are in the schools themselves: administrators, educators, and students.

Finnigan [52] provided some specific actions administrators could do to promote teacher motivation at their schools. Among those suggestions are (a) acquiring resources teachers need; (b) supporting teachers as they take risks for using new pedagogies; and (c) understanding how students' progress is tracked.

School district leaders also receive guidance from personnel at the state and federal levels, particularly pertaining to the desired outcomes for students regarding state assessment scores. It may be that personnel at varied leadership levels, including policy makers who may or may not realize the impact of policies at the school level, need to become more aware of what teachers and students are doing to achieve AYP status. Perhaps the further away from the classroom that leaders are (e.g., school-based administrators compared to federal policy makers) influences the degree to which leaders see the need to interest in knowing how to motivate educators responsible for students' scores for AYP. Studies 
that illuminate how teachers feel can provide near- and distallevel leaders with valuable information from which to develop responsive actions. Additionally, Eyal and Roth [53] note that providing autonomy to teachers is important, suggesting that teachers are included when determining responsive actions.

4.3. AYP Impact on Teacher Motivation. Finnigan and Gross [6] suggested that policy makers examine the perceived and real adverse impacts on educators who teach in schools that have not achieved AYP, noting that the desired impact on teacher motivation variables of failure to achieve AYP is not consistently or positively occurring. This Teacher Motivation Survey research is responsive to Finnigan and Gross' suggestion for further examination of this issue, including that the results seem counterintuitive to what is expected regarding teacher motivation at AYP Yes and AYP No schools (e.g., lower teacher motivation from educators at AYP No schools is generally expected, but that is not consistent with results from the present study).

In the present study, the qualitative analyses of responses to open-ended questions enable us to hear individual participants' voices. After having responded to multiple open-ended questions and asked if they had any other content they wanted to tell the researchers, educators still kept writing to us. Their comments return us to the survey's themes of self-efficacy, collective efficacy, and career satisfaction, and they remind us of how critical it is to have effective school-based administrators. As Mintrop and Sunderman [54] noted, "schools cannot be improved against the better judgment, and without the enthusiastic participation, of those charged with making the improvements" (p. 361). Educators are charged to make those improvements, and their enthusiastic participation depends on their motivation.

4.4. Limitations. Generalization of this research is limited as participants were from only two Mid-Atlantic States. Additionally, only the teachers in schools with accessible email lists were included through Market Data Retrieval and the rate of nondeliveries of the survey is not known to the researchers. The low response rate coupled with concerns regarding nonresponse bias also suggests caution about generalizing beyond these participants. Although the Teacher Motivation Survey was completed anonymously by participants, the nature of survey research assumes honesty and accuracy in responses, which cannot be verified.

4.5. Future Research. Replication of this research with educators teaching varied grade levels and in different teaching positions (e.g., third-grade general educators, eighthgrade science teachers) is necessary to determine both how well the Teacher Motivation Survey as an instrument is able to acquire information described in this study and to identify similarities and differences in responses. Gathering information from educators at schools that have or have not achieved AYP is essential to ensure these educators' voices are heard and that their input is heeded. In particular, comparisons among the three domains of Work Environment (collective efficacy), individual Professional Identity (selfefficacy), and Career Satisfaction enabled us to determine more specific areas for attention. To extend our knowledge further, a larger and more representative educator sample, to include additional geographic locations, is needed, along with acquiring more in-depth qualitative data (e.g., focus interviews). Additionally, as Finnigan and Daly [9] have done, continued examination is warranted to determine any changes per teachers' motivation may have occurred given the evolution of NCLB's operationalization since its origination.

Just as educators' work is to adjust instruction to be responsive to students' needs, this research provides some insights into areas where policy makers and administrators might adjust their actions to be responsive to teachers' needs for motivation. Future research could examine perspectives from school-based administrators regarding their perceptions and actions toward maintaining or increasing motivation for educators at their respective schools. Conversely, it is also important to examine motivation factors for schoolbased administrators, perhaps via a companion to the TMS survey, but designed for administrators. Foley and Nelson [55], for example, found that middle school administrators in their sample who were at AYP No schools for two consecutive years rated their job satisfaction as low. Two of the factors contributing to that rating were the pressure to achieve AYP and the amount of time administrators spent on AYP-related tasks.

Given the pressures to attain and retain AYP Yes status in U.S. schools, it is logical that motivation for school-based administrators and educators in their schools may be affected similarly, particularly for those at schools who have failed to acquire AYP status for more than one year. Although it may be quite challenging to invest time and energy during the school year to teach students content assessed on states' assessments, it can be all the more demoralizing to have made that investment and not have it pay off. Consequently, identifying and implementing methods to motivate teachers and their administrators can be a sound investment for school systems. Further research could focus on revealing methods for motivating the professionals tasked with ensuring students achieve, particularly for professionals at AYP No schools.

Although this research was conducted in the USA and examined AYP status that is unique to the USA, the influences on teacher motivation are universal from an international perspective. For example, Klassen [56] examined job stress and job satisfaction related to collective efficacy for elementary and secondary teachers in Canada. He found that student discipline was a mediator for job stress and, subsequently, for job satisfaction. Klassen suggested that collective efficacy, as attributed to student behavior, could lower job stress. Gocke [28] elicited survey responses from educators in a province in Turkey, and his findings revealed that teachers' motivation was influenced by their needs to increase performance in the teaching-learning process. E. M. Skaalvik and S. Skaalvik (2010) found that elementary and middle school teachers in Norway identified six factors that influenced their job satisfaction as well as their career decision to remain a teacher 
or not. As such, factors that are malleable and can be influenced by actions that increase teachers' motivation, job satisfaction, and decision to remain in the teaching profession are well worth continued examination so that ultimately students are taught by highly-motivated teachers.

\section{Conflict of Interests}

The authors declare that there is no conflict of interests regarding the publication of this paper.

\section{References}

[1] “No Child Left Behind Act of 2001," 20 U.S.C. $\$ 6301$ et seq., 2001.

[2] U.S. Department of Education, ESEA Blueprint for Reform, Office of Planning, Evaluation, and Policy Development, Washington, DC, USA, 2010.

[3] U.S. Department of Education, Report to Congress on the Elementary and Secondary Education Act, School Year 2009-10, Office of Elementary and Secondary Education, Washington, DC, USA, 2012.

[4] A. Duncan, "Education reform's moon shot," Washington Post, 2009, http://www.washingtonpost.com/wp-dyn/content/story/ 2009/07/23/ST2009072302669.html.

[5] S. W. Hemelt, "Performance effects of failure to make Adequate Yearly Progress (AYP): evidence from a regression discontinuity framework," Economics of Education Review, vol. 30, no. 4, pp. 702-723, 2011.

[6] K. S. Finnigan and B. Gross, "Do accountability policy sanctions influence teacher motivation? Lessons from Chicago's low-performing schools," American Educational Research Journal, vol. 44, no. 3, pp. 594-630, 2007.

[7] R. D. Goddard, W. K. Hoy, and A. W. Hoy, "Collective efficacy beliefs: theoretical developments, empirical evidence, and future directions," Educational Researcher, vol. 33, no. 3, pp. 313, 2004.

[8] K. F. Wheatley, "The case for reconceptualizing teacher efficacy research," Teaching and Teacher Education, vol. 21, no. 7, pp. 747766, 2005.

[9] K. S. Finnigan and A. J. Daly, "Mind the gap: organizational learning and improvement in an underperforming urban system," American Journal of Education, vol. 119, no. 1, pp. 41-71, 2012.

[10] A. Katsiyannis, D. Zhang, J. B. Ryan, and J. Jones, "High-stakes testing and students with disabilities: challenges and promises," Journal of Disability Policy Studies, vol. 18, no. 3, pp. 160-167, 2007.

[11] D. van Garderen, A. Scheuermann, C. Jackson, and D. Hampton, "Supporting the collaboration of special educators and general educators to teach students who struggle with mathematics: an overview of the research," Psychology in the Schools, vol. 46, no. 1, pp. 56-77, 2009.

[12] K. K. Wong, "Politics and governance: evolving systems of school accountability," Educational Policy, vol. 27, no. 2, pp. 410421, 2013.

[13] R. S. Davies, "AYP accountability policy and assessment theory conflicts," Mid-Western Educational Researcher, vol. 21, no. 4, pp. 2-8, 2008.

[14] M. Byrd-Blake, M. O. Afolayan, J. W. Hunt, M. Fabunmi, B. W. Pryor, and R. Leander, "Morale of teachers in high poverty schools: a Post-NCLB mixed methods analysis," Education and Urban Society, vol. 42, no. 4, pp. 450-472, 2010.

[15] B. S. Billingsley, "Special education teacher retention and attrition: a critical analysis of the research literature," Journal of Special Education, vol. 38, no. 1, pp. 39-55, 2004.

[16] S. E. Eckes and J. Swando, "Special education subgroups under NCLB: issues to consider," Teachers College Record, vol. 111, no. 11, pp. 2479-2504, 2009.

[17] C. Rosas and L. Campbell, "Who's teaching math to our most needy students? A descriptive study," Teacher Education \& Special Education, vol. 33, no. 2, pp. 102-113, 2010.

[18] R. Zambo and D. Zambo, "The impact of professional development in mathematics on teachers' individual and collective efficacy: the stigma of underperforming," Teacher Education Quarterly, vol. 35, pp. 159-168, 2008.

[19] M. A. Tchoshanov, "Relationship between teacher knowledge of concepts and connections, teaching practice, and student achievement in middle grades mathematics," Educational Studies in Mathematics, vol. 76, no. 2, pp. 141-164, 2011.

[20] H. C. Hill, B. Rowan, and D. L. Ball, "Effects of teachers' mathematical knowledge for teaching on student achievement," American Educational Research Journal, vol. 42, no. 2, pp. 371-406, 2005.

[21] A. Kajander, "Elementary mathematics teacher preparation in an era of reform: the development and assessment of mathematics for teaching," Canadian Journal of Education, vol. 33, no. 1, pp. 228-255, 2010.

[22] H. C. Hill, "Mathematical knowledge of middle school teachers: implications for the no child left behind policy initiative," Educational Evaluation and Policy Analysis, vol. 29, no. 2, pp. 95-114, 2007.

[23] M. A. Winters, B. L. Dixon, and J. P. Greene, "Observed characteristics and teacher quality: impacts of sample selection on a value added model," Economics of Education Review, vol. 31, no. 1, pp. 19-32, 2012.

[24] A. Bandura, "Exercise of human agency through collective efficacy," Current Directions in Psychological Science, vol. 9, no. 3, pp. 75-78, 2000.

[25] A. Bandura, "Social cognitive theory: an agentic perspective," Annual Review of Psychology, vol. 52, pp. 1-26, 2001.

[26] A. Bandura, "Toward a psychology of human agency," Perspectives on Psychological Science, vol. 1, no. 2, pp. 164-180, 2006.

[27] A. W. Hoy and R. B. Spero, "Changes in teacher efficacy during the early years of teaching: a comparison of four measures," Teaching and Teacher Education, vol. 21, no. 4, pp. 343-356, 2005.

[28] F. Gokce, "Assessment of teacher motivation," School Leadership and Management, vol. 30, no. 5, pp. 487-499, 2010.

[29] J. C. Turner, K. B. Warzon, and A. Christensen, "Motivating mathematics learning: changes in teachers' practices and beliefs during a nine-month collaboration," American Educational Research Journal, vol. 48, no. 3, pp. 718-762, 2011.

[30] H. Ware and A. Kitsantas, "Teacher and collective efficacy beliefs as predictors of professional commitment," The Journal of Educational Research, vol. 100, no. 5, pp. 303-310, 2007.

[31] M. H. Fisher, "Factors influencing stress, burnout, and retention of secondary teachers," Current Issues in Education, vol. 14, no. $1,2011$.

[32] E. M. Skaalvik and S. Skaalvik, "Teacher self-efficacy and teacher burnout: a study of relations," Teaching and Teacher Education, vol. 26, no. 4, pp. 1059-1069, 2010. 
[33] G. Stephanou, G. Gkavras, and M. Doulkeridou, "The role of teachers' self- and collective-efficacy beliefs on their job satisfaction and experienced emotions in school," Psychology, vol. 4, no. 3, pp. 268-278, 2013.

[34] G. W. Rigol and C. Ziemnicki, Email Trends in the Education Market 2010: A Comprehensive Analysis of the 2008-2009 School Year, MDR, Shelton, Conn, USA, 2010.

[35] A. L. Sullivan, L. Long, and M. Kucera, "A survey of school psychologists' preparation, participation, and perceptions related to positive behavior interventions and supports," Psychology in the Schools, vol. 48, no. 10, pp. 971-985, 2011.

[36] J. R. Halbesleben and M. V. Whitman, "Evaluation survey quality in health services research: a design framework for assessing non-response bias," Health Services Research, vol. 48, no. 3, pp. 913-930, 2013.

[37] S. Aud, W. Hussar, G. Kena et al., The Condition of Education 2011 (NCES 2011-033). U.S. Department of Education, National Center for Education Statistics, U.S. Government Printing Office, Washington, DC, USA, 2011.

[38] P. H. Baker, "Managing student behavior: how ready are teachers to meet the challenge?" American Secondary Education, vol. 33, no. 3, pp. 51-64, 2005.

[39] A. Bandura, "Perceived self-efficacy in cognitive development and functioning," Educational Psychologist, vol. 28, no. 2, pp. 117-148, 1993.

[40] A. Brouwers and W. Tomic, "The factorial validity of the teacher interpersonal self-efficacy scale (report SP038950)," ERIC Document Reproduction Service No. ED437365, Netherlands Open University, Heerlen, The Netherlands, 1999.

[41] S. Gibson and M. H. Dembo, "Teacher efficacy: a construct validation," Journal of Educational Psychology, vol. 76, no. 4, pp. 569-582, 1984.

[42] B. G. Glaser and A. L. Strauss, The Discovery of Grounded Theory: Strategies for Qualitative Research, Aldine, Chicago, Ill, USA, 1967.

[43] J. Stillman, "Teacher learning in an era of high-stakes accountability: productive tension and critical professional practice," Teachers College Record, vol. 113, no. 1, pp. 133-180, 2011.

[44] K. Viel-Ruma, D. Houchins, K. Jolivette, and G. Benson, "Efficacy beliefs of special educators: the relationships among collective efficacy, teacher self-efficacy, and job satisfaction," Teacher Education \& Special Education, vol. 33, no. 3, pp. 225233, 2010.

[45] J. S. Wills and J. H. Sandholtz, "Constrained professionalism: dilemmas of teaching in the face of test-baseda accountability," Teachers College Record, vol. 111, no. 4, pp. 1065-1114, 2009.

[46] R. Gajda and M. Militello, "Recruiting and retaining school principals: what we can learn from practicing administrators," Journal of Scholarship and Practice, vol. 5, no. 2, pp. 14-20, 2008.

[47] M. C. Partlow and C. S. Ridenour, "Frequency of principal turnover in Ohio schools," Mid-Western Educational Researcher, vol. 21, no. 2, pp. 15-23, 2008.

[48] M. Coelli and D. A. Green, "Leadership effects: school principals and student outcomes," Economics of Education Review, vol. 31, no. 1, pp. 92-109, 2012.

[49] G. E. Hall and S. M. Hord, Implementing Change: Patterns, Principles, and Potholes, Pearson, Boston, Mass, USA, 3rd edition, 2011.

[50] K. Leithwood and D. Jantzi, "Linking leadership to student learning: the contributions of leader efficacy," Educational Administration Quarterly, vol. 44, no. 4, pp. 496-528, 2008.
[51] Center on Education Policy, Many Schools and Districts Have Not Made Adequate Yearly Progress? Four-Year Trends, Center on Education Policy, Washington, DC, USA, 2010, http://www.cep-dc.org/publications/index.cfm?selectedYear= 2010.

[52] K. S. Finnigan, "Principal leadership and teacher motivation under high-stakes accountability policies," Leadership and Policy in Schools, vol. 9, no. 2, pp. 161-189, 2010.

[53] O. Eyal and G. Roth, "Principals' leadership and teachers' motivation: self-determination theory analysis," Journal of Educational Administration, vol. 49, no. 3, pp. 256-275, 2010.

[54] H. Mintrop and G. L. Sunderman, "Predictable failure of federal sanctions-driven accountability for school improvement-and why we may retain it anyway," Educational Researcher, vol. 38, no. 5, pp. 353-364, 2009.

[55] G. Foley and S. Nelson, "The impact of annual yearly progress on middle school principals' job satisfaction," National Forum of Educational Administration \& Supervision Journal, vol. 28, no. 2, pp. 27-50, 2011.

[56] R. M. Klassen, "Teacher stress: the mediating role of collective efficacy beliefs," The Journal of Educational Research, vol. 103, no. 5, pp. 342-350, 2010. 